\title{
Impact of Cervix Uterine Cancer Screening in the Indian Park of Xingu
}

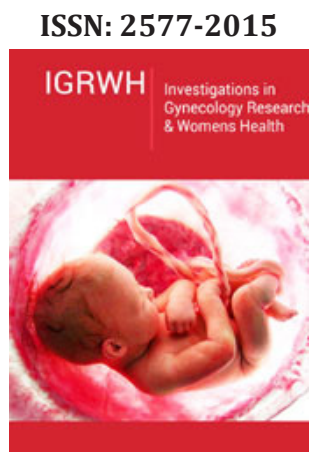

*Corresponding author: Góis Speck NM, Departamento de Ginecologia, Brasil

Submission: 酶 October 23, 2019

Published: 址 November 07, 2019

Volume 3 - Issue 2

How to cite this article: Carvalho $\mathrm{S} A \mathrm{C}$ Regina C C, Kesselring T F, Douglas R, Longatto F A, Franco M F, Azevedo F GR, Lascasas R JC, Góis Speck NM. Impact of Cervix Uterine Cancer Screening in the Indian Park of Xingu. Invest Gynecol Res Women's Health.3(2). IGRWH.000559.2019.

DOI: 10.31031/IGRWH.2019.03.000559

Copyright@ Góis Speck NM, This article is distributed under the terms of the Creative Commons Attribution 4.0 International License, which permits unrestricted use and redistribution provided that the original author and source are credited.

\author{
Carvalho Scopin $\mathrm{AC}^{1}$, Regina Cinti $\mathrm{C}^{1}$, Kesselring Tso $\mathrm{F}^{1}$, Douglas Rodrigues ${ }^{2}$, \\ Longatto Filho $A^{3,4,5,6,7}$, Franco Munari $F^{2}$, Azevedo Focchi GR ${ }^{6}$, Lascasas Ribalta \\ JC ${ }^{1}$ and Góis Speck NM ${ }^{1 *}$ \\ ${ }^{1}$ Departamento de Ginecologia, Brasil \\ ${ }^{2}$ Departamento de Medicina Preventiva, Brasil \\ ${ }^{3}$ Molecular Oncology Research Center, Brasil \\ ${ }^{4}$ ICVS/3B's - PT Government Associate Laboratory, Brasil \\ ${ }^{5}$ Life and Health Sciences Research Institute (ICVS), Brasil \\ ${ }^{6}$ Department of Pathology, Faculty of Medicine, Brasil \\ ${ }^{7}$ Departamento de Patologia, Brasil
}

\begin{abstract}
Background: There are few exploratory studies on Human Papillomavirus (HPV) infection and cervical cancer in indigenous populations. Because these women represent a very peculiar population in terms of habits and cultural rituals of its own, HPV infection and its related-oncogenesis potential could not denote the same progression characteristics as compared to the other populations commonly studied. The aim of this study was to evaluate 13 years of cervical cancer screening actions and assistance in the Xingu Indigenous Park, through cytological analysis and DNA-HPV molecular test.
\end{abstract}

Methods: This is an observational, transversal and retrospective study conducted by data analysis of screening and control actions of uterine cervical HPV-associated lesions in the scope of the Xingu project supported by the Universidad Federal de São Paulo (UNIFESP), Brazil. The population studied consisted of indigenous, sexually active women, aged 11 years or older, belonging to sixteen ethnic groups residing in the middle, lower and east Xingu regions. The women were screening for conventional cervical screening test (Pap test) and HPV tests.

Results: The population coverage for cytological analyses in the entire period averaged $89.4 \%$. Only 3 cases of cervical cancer were documented over the 13 years of follow-up. The HPV positivity rate was $24.5 \%$ and latency $22.9 \%$.

Conclusions: It was observed that the high coverage of the population was valuable in maintaining the quality of screening because of the large number of normal Pap tests and rare cases of cancer compared to the national incidence.

Keywords: HPV; Xingu indigenous park; Cervical cancer screening; Indigenous; Uterine cervical cancer

Abbreviations: CEP: Ethics and Research Committee; CONEP: National Committee on Ethics and Research; CPOM: Molecular Oncology Research Center; DNA: Deoxyribonucleic acid; DSEI: Special indigenous sanitary District; E: Early region; EPM: Paulista School of Medicine; FUNASA: National Health Foundation; GE: General Eletric; HIV: Human immunodeficiency virus; HSIL: High-grade squamous intraepithelial lesion; HSP: Hospital São Paulo; HPV: Human papillomavirus; IBGE: Brazilian Institute of Geography and Statistics; IEP: Institute of Education and Research; ISA: Socio-Environmental Institute; L: Late region; LCR: Long control region; LSIL: Low-grade squamous intraepithelial lesion; NUPREV: Nucleus of Prevention of Gynecological Diseases; PCR: Polymerase chain reaction; PIX: Xingu Indigenous Park; PRB: Retinoblastoma protein; SESA: Special Secretariat of Indigenous health; SIASI: Indigenous health Care Information system; STI: Sexually transmitted infection; UBS: Basic health Unit; USMA: Health and Environment Unit; UNIFESP: Universidade Federal de São Paulo; WHO: World Health Organization

\section{Introduction}

The Brazilian indigenous population is estimated at approximately 817,963 people, with 444,75 thousand women, 269 of whom are of childbearing age. The medical attention to the indigenous health in Brazil has undergone several transformations ranging from accelerated changes in the epidemiological profile to the restructuring of the health care system itself [1]. Among the limitations of the system, there is still a far-reaching performance in the prenatal care, prevention of cervical cancer, prevention of sexually transmitted diseases, 
among others [1,2]. In addition, available epidemiological data are insufficient to assess the health problems of the female population and of indigenous adolescents [3]. There is a significant lack of data regarding the incidence of cervical lesions in this population. This issue is particularly important because in Brazil, cervical cancer account for 16,340 new cases per year; globally, it is the fourth most common type of female cancer, with an estimated incidence of 527,000 more cases, annually [4]. Human papillomavirus (HPV) is the most common sexually transmitted infectious agent (STI) in adolescents and young adults worldwide, and the persistent infection of HPV oncogenic types is the most important risk factor for the development of uterine cervical neoplasms.

HPV is highly prevalent in sexually active women less than 25 years of age, affects about 5 to $40 \%$ of women of reproductive age as asymptomatic cervical infection and can infect about $75 \%$ of adults throughout their lives [5-8]. A study of the natural history of HPV infection shows that more than $50 \%$ of young women, after three years of sexual debut, will become positive for HPV DNA tests [9]. HPV is a necessary cause for the development of cervical cervix, but other risk factors may be associated with disease progression, such as female sexual behavior, partner sexual behavior, smoking, multiplicity of sexual partners, multiparity, early sexual initiation, use of oral contraceptives for five years or more, and coinfection with other infectious agents such as human immunodeficiency virus (HIV), Chlamydia trachomatis and Herpes simplex virus $[4,10]$. Cervical carcinoma maintains high rates among indigenous women worldwide, including in developed countries where mortality from the disease is also higher among aborigines. There are few epidemiological studies on cervical lesions induced by HPV infection in American Indian populations [11]. Some authors suggest that the low coverage of the tracing is mainly due to tribal cultural issues and geographical barriers [12-15]. Indigenous women are at high risk for HPV infection and are at higher risk for cancer due to cultural behavioral patterns, the way they experience sexuality, and contact with the surrounding not-indigenous population. In general, the early female sexual intercourse, high fertility rates, the occurrence of multiple and promiscuous sexual partners throughout the life, immunodeficiencies, unfavorable socioeconomic status and history of STIs stand out in the Brazilian female indigenous population [16].

These risk factors, associated with poor access to health services and lack of information, facilitate both HPV infection and cervical cancer progression $[17,18]$. Some studies point to cervical cancer as one of the main causes of morbidity and mortality in these populations [19]. The natural history of HPV infection in these women, however, is not yet well established. There are not enough studies to understand the evolution of the infectious/neoplastic process, whether there is or not the virus whitening in the same way as occurs in the other ethnicities and if the cofactors negatively interfere in viral elimination [17]. The objective of this study was to evaluate the impact of the actions related to the cytological and molecular screening for the detection of precursor lesions and cervical cancer in the Xingu indigenous park.

\section{Materials and Methods}

This was a retrospective observational study of the Paulist School of Medicine of the Federal University of São Paulo-EPMUNIFESP, conducted at the Health and Environment Unit (USMA) of the Department of Preventive Medicine and the Nucleus of Prevention of Gynecological Diseases (NUPREV), in association to the Department of Gynecology and Department of Pathology, as well as Molecular Oncology Research Center (CPOM) of the Institute of Education and Research (IEP) of the Hospital de Cancer de Barreto, that performed the DNA-HPV test.

\section{Ethics}

The project was evaluated and approved by the Ethics and Research Committee of UNIFESP-EPM under number CEP 0549/08 and by the National Commission of Ethics in Research (CONEP) number 14950. Because it was a retrospective study that did not reveal the patients' identity or any of their personal data, and since there were no implicit impairments to the women and the results from the project could benefit other women in the future, there was no need to sign a term of confidentiality by the patients; however, a consent form was established for the leaders of the villages in question, in accordance to the CONEP determination.

\section{Population enrolled}

The results of the cytological tests collected in the population of sexually active women from the determined areas of Middle, Lower and East Xingu comprised a total of 600 women in each tracking action, totaling 4,044 Pap tests from 2005 to 2014. In the years 2015, 2016 and 2017, only control actions were performed on women who had a previous history of cytological abnormalities, by assessing 477 cervical samples.

\section{Pap tests}

A cervical-vaginal sample were collected with Ayre-type wooden spatula and endocervical brush with endocervical brush. The smears were alcohol-fixed and stained by the Papanicolaou technique. The Bethesda System terminology was used to classify the cytological findings $[20,21]$. Low-grade intraepithelial lesions (LSIL) includes atypical squamous cells of uncertain significance and LSIL in order to facilitate statics.

\section{Selection of HPV tests samples}

574 from 590 samples stored at- $80{ }^{\circ} \mathrm{C}$ were tested for the MY9/ MY11 genes by PCR. Quality of samples were verified assessing beta globin gene: 16 samples tested negative for beta globin were excluded.

\section{DNA extraction}

DNA extraction was performed according to the protocol of the GE® Genomic Prep ${ }^{\mathrm{TM}}$ Blood Kit for materials from blood and epithelial cell scrapings. It was started by adding $20 \mu$ of proteinase $\mathrm{K}$ in a microtube containing $300 \mu \mathrm{l}$ of cell pellet. $400 \mu \mathrm{l}$ of lysis solution was then added to the tube. It was stirred for a few moments and incubated for 10 minutes at room temperature. The whole volume was transferred to a mini affinity column and centrifuged 
at 14,000 RPM's for 3 minutes. All filtered material was discarded, and the column washed 2 times, the first one with $500 \mu \mathrm{l}$ of lysis solution and the second with $500 \mu \mathrm{l}$ of wash solution. All filtered was discarded and the mini column transferred to a new dry microtube. $120 \mu \mathrm{l}$ of elution solution (prewarmed pure water at $70{ }^{\circ} \mathrm{C}$ ) was then added and incubated for 1 minute at room temperature and then centrifuged at 14,000 RPM's for 1-minute, remaining filtrate corresponding to the genomic DNA. The purified DNA was stored at- $80{ }^{\circ} \mathrm{C}$ until use. The amount of DNA in each sample was measured by spectrophotometry on a NanoDrop® 2000 (full spectrum spectrophotometer-Spectronic $®$ model Genesy 5).

\section{PCR MY9/MY11 assay}

For each PCR sample, 100 ng DNA, 10pmol of each primer (MY9 / 11), $10 \mu$ l GoTaq ${ }^{\circledR}$ Green Master Mix (Promega, Madison, WI, USA)) and distilled water were added to make up to $20 \mu$ l. For the amplification conditions, an initial denaturation cycle of $94^{\circ} \mathrm{C}$ for 5 minutes was used, followed by 35 cycles at $94^{\circ} \mathrm{C}$ for 30 seconds, 56 ${ }^{\circ} \mathrm{C}$ for 30 seconds and $72{ }^{\circ} \mathrm{C}$ for 30 seconds, and final extension of 72 ${ }^{\circ} \mathrm{C}$ for 5 minutes. The PCR amplification products were loaded onto a 2.0\% agarose gel (Amersham Pharmacia Biotech), stained with ethidium bromide $(1 \mu \mathrm{g} / \mathrm{ml})$ and subjected to electrophoresis for 20 minutes at $110 \mathrm{~V}$ in a horizontal vessel containing TAE run buffer $1 \mathrm{X}$ (Tris Acetate $0.04 \mathrm{M}, 1 \mathrm{mM}$ EDTA pH8). The visualization of the amplified fragment was done in transilluminator of ultraviolet light with photo documented through the system "Kodak Digital Science 1D". Positive samples were characterized by the presence of the $440 \mathrm{bp}$ fragment with the objective of identifying HPV DNA without genotyping [22].

\section{Statistical method}

The variables of interest were compared using Qui-Square and Likelihood Ratio tests. The level of statistical significance considered in this study was $5 \%$ (p-value $\leq 0.05$ ).

\section{Result}

In 2005, 2007, 2009, 2010 to 2014, cervical cancer screening actions were performed at the Xingu Indigenous Park (PIX), with the collection of 4,047 cytological exams performed in sexually active women, reaching coverage average of $89.4 \%$ of the population. In the years 2005 and 2010, the highest number of cytological abnormalities occurred, and the finding of high-grade intraepithelial lesions and cancer (HSIL+) appeared in greater number in 2005 as depicted in Table1. There were 3 cases of invasive cervical cancer during the study period, two in 2005. It is also observed a decrease of HSIL over the years that had its largest number in 2005, when the first action of qualified professionals was performed.

Table 1: Cervicovaginal cytology results from years 2005 to 2014 in the xingu park.

\begin{tabular}{|c|c|c|c|c|c|c|c|c|}
\hline Diagnosis $\backslash$ Year & $\mathbf{2 0 0 5}$ & $\mathbf{2 0 0 7}$ & $\mathbf{2 0 0 9}$ & $\mathbf{2 0 1 0}$ & $\mathbf{2 0 1 2}$ & $\mathbf{2 0 0 5}$ & $\mathbf{2 0 1 4}$ & Total \\
\hline Normal & $453(87.5 \%)$ & $530(94 \%)$ & $563(95.4 \%)$ & $543(87 \%)$ & $550(90.6 \%)$ & $593(96.1 \%)$ & $497(94.3 \%)$ & $3729(92.1 \%)$ \\
\hline LSIL & $41(7.9 \%)$ & $29(5.1 \%)$ & $17(2.9 \%)$ & $70(11.2 \%)$ & $44(7.2 \%)$ & $16(2.6 \%)$ & $23(4.4 \%)$ & $240(1.5 \%)$ \\
\hline HSIL+ & $24(4.6 \%)$ & $5(0.9 \%)$ & $10(1.7 \%)$ & $11(1.8 \%)$ & $13(2.1 \%)$ & $8(1.3 \%)$ & $7(1.3 \%)$ & $78(0.5 \%)$ \\
\hline
\end{tabular}

Chi square test: $\mathrm{p}<0.0001$

Table 2: Correlation between age and cytological findings in 10 years of cervical cancer screening (2005-2014) in the xingu park.

\begin{tabular}{|c|c|c|c|c|}
\hline Diagnosis & $\mathbf{< 4}$ years & $\mathbf{2 5 - 6 3}$ years & $\mathbf{2 6 4}$ years & Total \\
\hline Normal & $1716(92 \%)$ & $1862(92,4 \%)$ & $151(91 \%)$ & $3729(92,1 \%)$ \\
\hline LSIL & $125(6,7 \%)$ & $107(5,3 \%)$ & $8(4,8 \%)$ & $240(5,9 \%)$ \\
\hline HSIL+ & $25(1,3 \%)$ & $46(2,3 \%)$ & $7(4,2 \%)$ & $78(1,9 \%)$ \\
\hline Total & $1866(100 \%)$ & $2015(100 \%)$ & $166(100 \%)$ & $4047(100 \%)$ \\
\hline
\end{tabular}

Chi square test: $\mathrm{p}<0,0001$

Table 3: Correlation of the DNA-HPV test and cytological findings in the year 2009 in the Xingu Park. Likelihood Ratio Test: $\mathrm{p}<0,0165$.

\begin{tabular}{|c|c|c|c|}
\hline Diagnosis & HPV Positive & HPV Negative & Total \\
\hline Normal & $132(23.7 \%)$ & $425(76.3 \%)$ & $557(100 \%)$ \\
\hline LSIL & $3(37.5 \%)$ & $5(62.5 \%)$ & $8(100 \%)$ \\
\hline HSIL+ & $7(77.8 \%)$ & $2(22.2 \%)$ & $9(100 \%)$ \\
\hline Total & $142(24.7 \%)$ & $432(75.3 \%)$ & $574(100 \%)$ \\
\hline
\end{tabular}

The comparison between the variables age and cytological findings demonstrated, as expected, that patients younger than 24 years had a higher percentage of LSIL and patients over 64 presented a higher percentage of HSIL (Table2). In the years 2015, 2016 and 2017 only control actions were performed, that is, the tests were performed in cases of patients who had previous cytological alterations or who were treated for some cervical lesion. There was no statistical difference between LSIL and HSIL frequencies between the ages. In the 2009 cervical material was preserved in an appropriated liquid medium for DNA-HPV testing. Table 3 show the frequencies of HPV positive tests distributed according to the cytological abnormalities. 


\section{Discussion}

The results herein reported demonstrated that indigenous population is prone to be highly exposed to the HPV infection. The results we obtained are comparable to the worse data from areas seriously affected by HPV infection. Studies on indigenous women's health are scarce, which makes it difficult to structure health actions in this population. Some characteristics of the biopsychosocial behavior of indigenous societies favor the exposure of this population to the risk factors for STI and cervical abnormalities, including cervical cancer. In the indigenous peoples of the Xingu and among others it is common the conjugal union at very young age, most often combined between the parents, which can explain, in part, the high prevalence of HPV infection we found. It is wellknown that in the indigenous women living in Middle, Lower and East Xingu, early beginning of the reproductive life, around the 15 years old. As the exercise of sexuality and conception is precocious, the reproductive period of these women, for the most part, lasts about thirty years, with high fertility rates [19].

The peculiarities in the care of women in the Xingu, such as the presence of an interpreter for communication, the geographic isolation with great difficulty of access of the teams to the places of care and the inequality of the information received, molded all planning, organization and structuring for the prevention of cervical cancer over the years [16]. Facing these findings, and considering all the cultural variables described previously, the current study attempted to involve indigenous women, sexually active, from the youngest 11 years old girl to older women belonging to sixteen ethnic groups living in the Xingu regions. The objective of the cervical cancer control program in the Xingu is the early detection of precursor lesions and, thus, provide appropriate and timely treatment for indigenous women. This activity is based on the Cervical Cancer Care Line proposed by the Brazilian Ministry of Health that determines humanized and comprehensive access to actions and services qualified to promote disease prevention [23]. Even in developed countries with well-established screening programs, indigenous populations have a higher incidence of cancer cervical, maybe due to similar reasons. This fact can be perceived in studies developed with Aborigines in Australia, Canada and the United States of America [13,24].

Countries with a cervico-vaginal cytology test frequency greater than $70 \%$ with a period of 3 to 5 years present reduced rates of death among women [25]. The tracking rates observed in Xingu after beginning the joint work between the NUPREV team and the Xingu Project are only found in developed countries with well-established population screening programs. Because cervicalvaginal cytology is still one of the most widely used strategies for screening for cervical cancer in Brazilian territory, achieving high population coverage is the most important factor in reducing cervical cancer incidence and mortality. In this perspective, the objective of Xingu Project was reached with great success in the screening of the indigenous population $[16,18]$. Throughout the 13 years of observation and data collection of these women, it was possible to make changes in the inclusion criteria of the patients in the screening, in the attempt to aligned with the Brazilian guidelines since an excellent coverage of approximately $90 \%$ and a reduction in mortality due to cervical cancer, as well as precursor lesions, was attained. This data confronts other indigenous statistics in the country, which show a low coverage rate of the cervico-vaginal cytology exam, from 5.1 to $51 \%$, indicating the urgent need of prioritization of preventive measures to improve the prevention cervical cancer strategies in other indigenous women population $[26,27]$.

The change in the age of onset of screening for 18 years occurred in the Xingu in 2014 after one of the studies conducted has shown that the largest contingent of young women is below the age of 18 years. In this age group the treatment of the intraepithelial lesions is not indicated, thus avoiding an excess of coverage, "overtreatment" and waste of investments. The rationale for cervical cancer screening to be initiated earlier was the occurrence of lesions below the age of 25 years (data not published). If the assumption of many countries that the screening should start after the age of 25 , were adopted, some indigenous girls, even in a reduced number, would have serious cervical lesions for a long period up to reach the suggested age for screening. Moreover, the possibility of loss of these women, who constantly change villages and often change their names, would lead to discontinuity of follow-up [17].

In 2005, we identified the highest percentage of cervical lesions due to the beginning of the screening actions proposed by UNIFESP in the population in Xingu women. Patients younger than 24 years of age had a higher percentage of LSILs, since such transient cytological alterations are common in adolescents and young adults, usually at the beginning of sexual life. There are strong evidences that more than $90 \%$ of HPV-induced infections in adolescents' regress within 3 years [28-30]. Thus, after the beginning of the organized screening in Xingu, there was a decrease in the percentage of LSILs over the years, being in 2012 the action with the lowest percentage of all changes. The non-discriminative DNA-HPV test was performed in the 2009 samples for high and low oncogenic risk groups, in order to evaluate its outcome against cytological alterations, evidencing a greater number of alterations in those positive HPV. Some studies carried out in indigenous populations suggest a higher prevalence of HPV infection with rates ranging from 7 to $25 \%$, a risk that is commonly related to poor access to health services, cultural aspects and less vaccine coverage [24]. Because it is a test non-discriminative, there were a high number of HPV positive women with normal cytology (93\%). This fact is certainly biased, because the women were predominantly composed by a very young population since for women aged under 30 years increases the likelihood of test positivity, most of the time, without clinical expression and with a high possibility of regression $[28,31,32]$.

Conversely, HPV test may add value to cervical cancer screening since HPV positive patients also had a higher percentage of LSILs and may be cost-effective option for primary screening in older women. This study limitation was DNA-HPV performed without genotyping; new studies are already being conducted in this population but still 
no results. After the beginning the follow-up organized in the Xingu, there were only 3 cases of invasive carcinoma. The low incidence of cancer was due to screening and early treatment of precursor lesions when the quality assistance begins and there are no prior prevalence data in this population. Vaccination against HPV in girls between 9 and 13 years was instituted in 2013 according to the Ministry of Health and in the boys, the campaign started in 2017 at ages 12 to 14 years. In unpublished research conducted in Australia with young indigenous women, there was a $94 \%$ reduction in the prevalence of HPV types contained in the quadrivalent vaccine $(6,11,16$ and 18$)$ in relation to the pre-vaccine era [33]. In Xingu, it was reported the prevalence of HPV 52 and HPV types of possible high oncogenic risk in high grade lesions, inferring the possibility of a different epidemiological profile than expected. Consequently, the efficacy of immunization through the quadrivalent or nonvalent vaccine in this population should be considered judiciously [2]. In conclusion, the paradigm that organization is indeed the best step to implement cancer prevention was demonstrated. Unprecedent study in a population lacking in access to health, presenting high screening coverage, shows that a good structuring of care programs, seriousness in actions, respect for cultural diversity, orientation and approximation of teams to the specific population is mandatory.

\section{Acknowledgement}

The authors gratefully acknowledge Hospital de Câncer de Barretos and CAPES.

\section{Conflict of Interest statement}

There are no commercial or other associations that might pose a conflict of interest in connection with the submitted article.

\section{References}

1. Rodrigues DA (2005) The Xingu Project and the health care policy of indigenous peoples in Brazil. In: Xingu Indigenous Park Health, culture and history, Unifesp/Paulista School of Medicine, Brazil, p. 259-273.

2. Freitas VG, Focchi GR, Pereira ER, Levi JE, Speck NMG, et al. (2016) HPV genotyping and p16 expression in xingu indigenous park, Brazil. Genet Mol Res 15(3).

3. Brasil MS (2004) Política nacional de atenção integral à saúde da mulher: Princípios e diretrizes. Ministério da Saúde.

4. Instituto Nacional de Cancer José Alencar Gomes da Silva INCA (2016) Estimativa 2016: incidência de câncer no Brasil. Ministério da Saúde Inst Nac Cancer José Alencar Gomes da Silva.

5. Hausen HZ (2002) Papillomaviruses and cancer: from basic studies to clinical application. Nat Rev Cancer 2(5): 342-350.

6. Stanley M (2010) Pathology and epidemiology of HPV infection in females. Gynecol Oncol 117(2): S5-10.

7. Panatto D, Amicizia D, Trucchi C, Casabona F, Lai PL, et al. (2012) Sexual behaviour and risk factors for the acquisition of human papillomavirus infections in young people in Italy: suggestions for future vaccination policies. BMC Public Health 12(1): 623.

8. Monteiro DL, Trajano AJ, Silva KS, Russomano FB (2009) Incidence of cervical intraepithelial lesions in a population of adolescents treated in public health services in Rio de Janeiro, Brazil. Cad Saude Publica 25(5): 1113-1122.

9. Moscicki AB, Ellenberg JH, Vermund SH, Holland CA, Darragh T, et al. (2000) Prevalence of and Risks for cervical human papillomavirus infection and squamous intraepithelial lesions in adolescent girls: impact of infection with human immunodeficiency virus. Arch Pediatr Adolesc Med 154(2): 127-134.

10. Bosch X, Harper D (2006) Prevention strategies of cervical cancer in the HPV vaccine era. Gynecol Oncol 103(1): 21-24.

11. Tonon SA, Picconi MA, Zinovich JB, Nardari W, Mampaey M, et al. (2004) Human papillomavirus cervical infection in guarani Indians from the rainforest of Misiones, Argentina. Int J Infect Dis 8(1): 13-19.

12. Sankaranarayanan R (2014) Screening for cancer in low-and middleincome countries. Ann Glob Health 80(5): 412-417.

13. Wakewich P, Wood B, Davey C, Laframboise A, Zehbe I (2016) Colonial legacy and the experience of first nations women in cervical cancer screening: a Canadian multi-community study. Crit Public Heal 26(4): 368-380.

14. (2016) National Institute of Public Health (Mexico) M, National Center for Health Information and Documentation (Mexico). Public Health of Mexico 58: 104-117.

15. Leigh BA, Zúñiga PU, Maldonado LL, Brown BJ, Lörincz A, et al. (2017) Barriers to HPV self-sampling and cytology among low-income indigenous women in rural areas of a middle-income setting: a qualitative study. BMC Cancer 17(1): 734.

16. Speck NM, Pereira ÉR, Schaper M, Tso FK, De Freitas VG, et al. (2009) Uterine cervical neoplasia prevention in Parque Indigena do Xingu. Eur J Gynaecol Oncol 30(4): 415-417.

17. Speck NM de G, Pinheiro J da S, Pereira ER, Rodrigues D, Focchi GR de A, et al. (2015) Cervical cancer screening in young and elderly women of the Xingu Indigenous Park: evaluation of the recommended screening age group in Brazil. Einstein (São Paulo) 13(1): 52-57.

18. Globocan (2012) Estimated cancer incidence, mortality and prevalence worldwide in 2012. Section of Cancer Surveillance.

19. Pereira ER, Speck NM, Ribalta JC (2011) Prevenção do câncer do colo do útero em população feminina do parque indígena do xingu, Mato Grosso.

20. Apgar BS, Zoschnick L, Wright TC (2003) The 2001 bethesda system terminology. Am Fam Physician 68(10): 1992-1998.

21. Wright TC, Cox JT, Massad LS, Twiggs LB, Wilkinson EJ (2002) 2001 consensus guidelines for the management of women with cervical cytological abnormalities. Jama 287(16): 2120-2129.

22. Bauer HM, Ting Y, Greer CE, Chambers JC, Tashiro CJ, et al. (1991) Genital human papillomavirus infection in female university students as determined by a pcr-based method. JAMA 265(4): 472-477.

23. (2013) Primary Care Notebooks-Cervical and Breast Cancer Control. Brasilia: Ministry of Health.

24. Grimminger DCS, Bell MC, Muller CJ, Maher DM, Chauhan SC, et al. (2011) HPV infection among rural American Indian women and urban white women in South Dakota: an HPV prevalence study. BMC Infect Dis 11(1): 252.

25. Arbyn M, Rebolj M, Kok IMCM, Fender M, Becker N, et al. (2009) The challenges of organising cervical screening programmes in the 15 old member states of the European union. Eur J Cancer 45(15): 2671-2678.

26. Taborda WC, Ferreira SC, Rodrigues D, Stávale JN, Baruzzi RG (2000) Rastreamento do câncer de colo uterino em índias do Parque Indígena do Xingu, Brasil central. Rev Panam Salud Pública 7(2): 92-96.

27. Areias MAC (2007) Implementação do programa de saúde familiar indígena no estado de Mato Grosso do SUl. Universidade de Brasíli.

28. Moscicki AB, Palefsky J, Smith G, Siboshski S, Schoolnik G (1993) Variability of human papillomavirus dna testing in a longitudinal cohort of young women. Obstet Gynecol 82(4): 578-585.

29. Moscicki AB, Cox JT (2010) Practice improvement in cervical screening and management (PICSM): symposium on management of cervical abnormalities in adolescents and young women. J Low Genit Tract Dis 14(1): 73-80. 
30. Moscicki AB (2001) Risks for incident human papillomavirus infection and low-grade squamous intraepithelial lesion development in young females. JAMA 285(23): 2995-3002.

31. Wright TC, Stoler MH, Behrens CM, Sharma A, Zhang G, et al. (2015) Primary cervical cancer screening with human papillomavirus: End of study results from the ATHENA study using HPV as the first-line screening test. Gynecol Oncol 136(2): 189-197.
32. Tracht JM, Davis AD, Fasciano DN, Eltoum IEA (2017) Discrepant HPV/ cytology cotesting results: Are there differences between cytologynegative versus HPV-negative cervical intraepithelial neoplasia? Cancer Cytopathol 125(10): 795-805.

33. McGregor S, Saulo D, Brotherton JML, Liu BP, et al. (2018) Decline in prevalence of human papillomavirus infection following vaccination among Australian Indigenous women, a population at higher risk of cervical cancer: The VIP-I study. Vaccine 36(29): 4311-4316.

For possible submissions Click below: 